\title{
Artificial, Natural, Underlying Factors That Affect the Arctic Climate
}

\author{
Zhenzhou Weng \\ Guanghua Cambridge International School, Shanghai, China \\ Email: 769469045@qq.com
}

How to cite this paper: Weng, Z. Z. (2018). Artificial, Natural, Underlying Factors that Affect the Arctic Climate. Journal of Geoscience and Environment Protection, 6, 101-108. https://doi.org/10.4236/gep.2018.611008

Received: September 28, 2018

Accepted: November 18, 2018

Published: November 21, 2018

Copyright $\odot 2018$ by author and Scientific Research Publishing Inc. This work is licensed under the Creative Commons Attribution International License (CC BY 4.0).

http://creativecommons.org/licenses/by/4.0/

\begin{abstract}
In recent years, the Arctic climate has changed dramatically. This paper sums up the remarkable performance of climate change in the Arctic Circle by going deep into the Arctic Circle, collecting climate data and comparing it with previous years' data and literature. The factors affecting climate change in the Arctic Circle are discussed from three aspects: artificial factors, natural factors and potential factors. The study finds out that the main factors that affect the Arctic climate are the large amount of greenhouse gases emitted by human activities, the warming of tropical ocean currents, and the potential eruption of solar flares.
\end{abstract}

\section{Keywords}

The North Pole, Climate Change, Scientific Expeditions

\section{Introduction}

The Arctic has long given the impression that the summer is short and the winter is long and cold. With the continuous development and progress of human society and industry, the global temperature has increased year by year, and the atmosphere has been continuously weakened. It is the Arctic region that has been affected the most, because it is directly exposed to strong sunlight, making the region twice as hot as the rest of the world (Solomon et al., 2007). As a consequence, sea ice melts, leaving animals like polar bears without a place to live and destroying the ecosystems in the Arctic. This paper analyzes the factors that affect the Arctic climate through conducting a scientific expedition, collecting and sorting out data, comparing the literature and analyzing the factors that affect the climate of the Arctic Circle.

\section{Methods and Materials}

The scientific expedition was strongly supported by Professor Gao Dengyi, the 
first person in the polar scientific examination of China from the China Meteorological Center, the meteorologist Zhang Mingying, and Professor Ma Jingjin. A professional scientific research team was formed under the organization of these academic authorities. The team conducted a two-week expedition on the Arctic Svalbard Islands by taking the Polaris cruise ship.

In the scientific expedition, climate data were collected from Monaco Glacier, Consifjord and other places, and historical data and literature were obtained from Svalbard University, Barents Camp, New Oresson Arctic Scientific Base and local meteorological museums.

\subsection{Temperature Rising (Table 1)}

In camps such as Oslo, a high temperature of 28 degrees Celsius was measured in the field, a significant increase compared with the historical data for the camps. According to a report released by Met Office in Jan. 2017, the global average annual temperature continues to rise, up to 0.8 degrees Celsius from the 1980s to 2016 (shown in Figure 1).

\subsection{Glacier Melting}

According to historical data (Lindsay et al., 2014) from the Barents-Kara camp, the SIC of Barents-Kara has declined significantly since the twenty-first century (shown in Figure 2).

According to America's National Snow and Ice Data Centre, the Arctic ice sheet area has decreased by about 386,000 square miles in recent years, the glacier is retreating at a rate of 30 meters per year, the average daily retreat in July is about 106,000 square kilometers, which means the ice sheet has broken up, and the huge ice sheet is divided into two (Liu et al., 2012). And the thickness of the ice, according to Andy Lee Robinson, is estimated to have fallen by half since 1979, when satellite records began, and there is probably less ice floating on the Arctic Ocean now than at any time since a particularly warm period 8000 years ago, soon after the last ice age (shown in Figure 3).

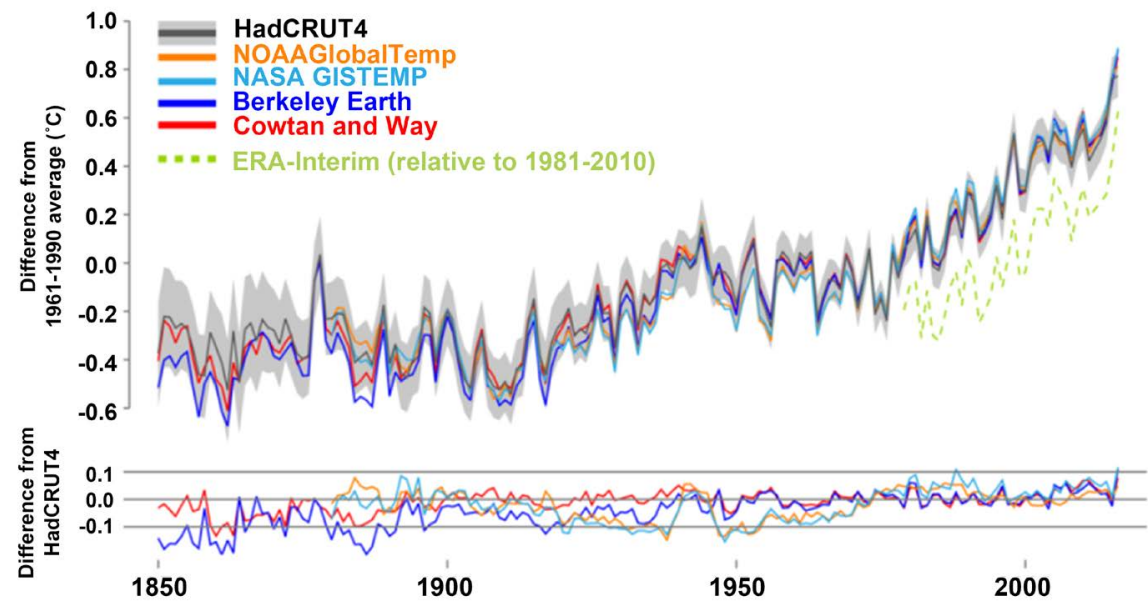

Figure 1. Global annual average temperature anomalies. 
(a) Borents - Koro SIC Anomoly

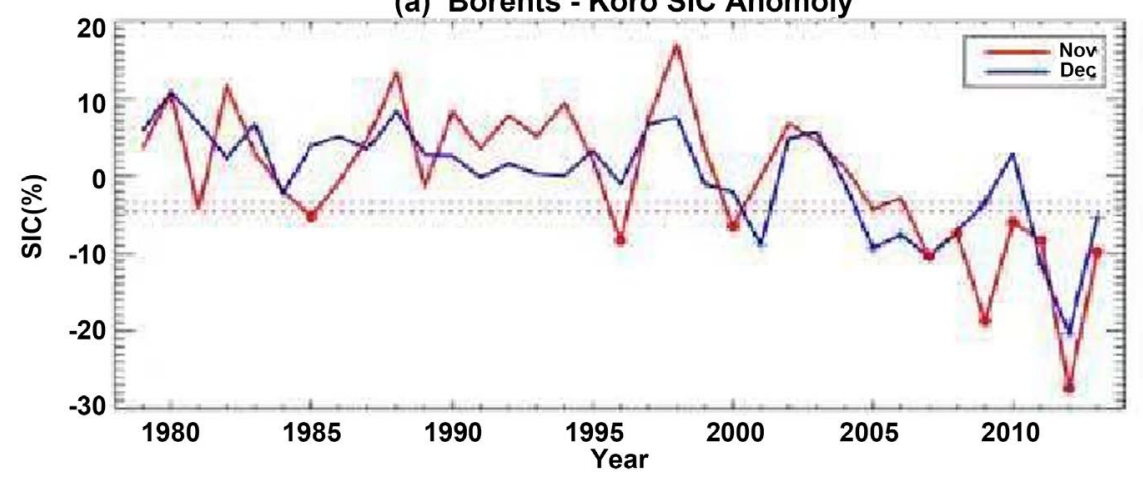

(b) Borents - Koro SIC Anomoly (ND)

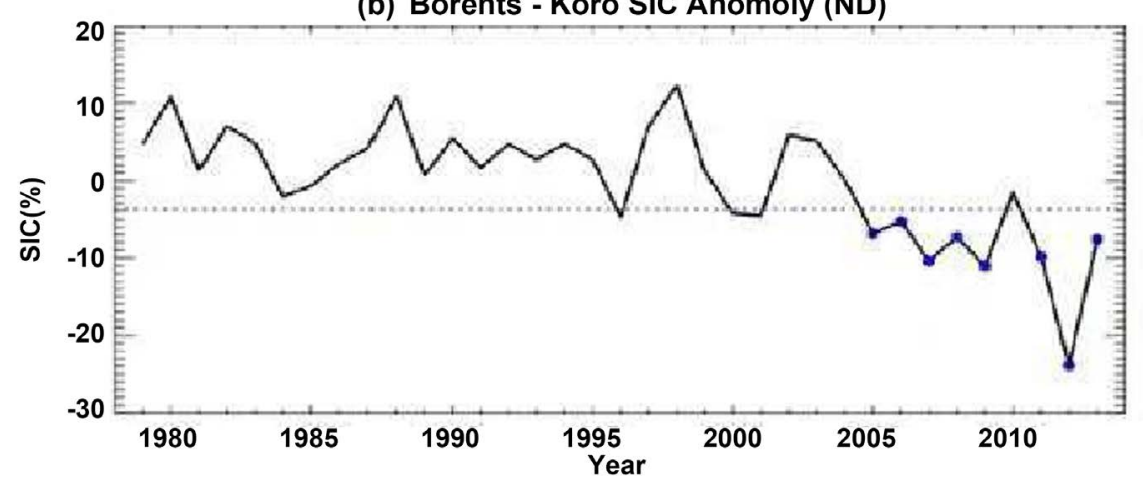

Figure 2. Barents-Kara SIC Anomaly.

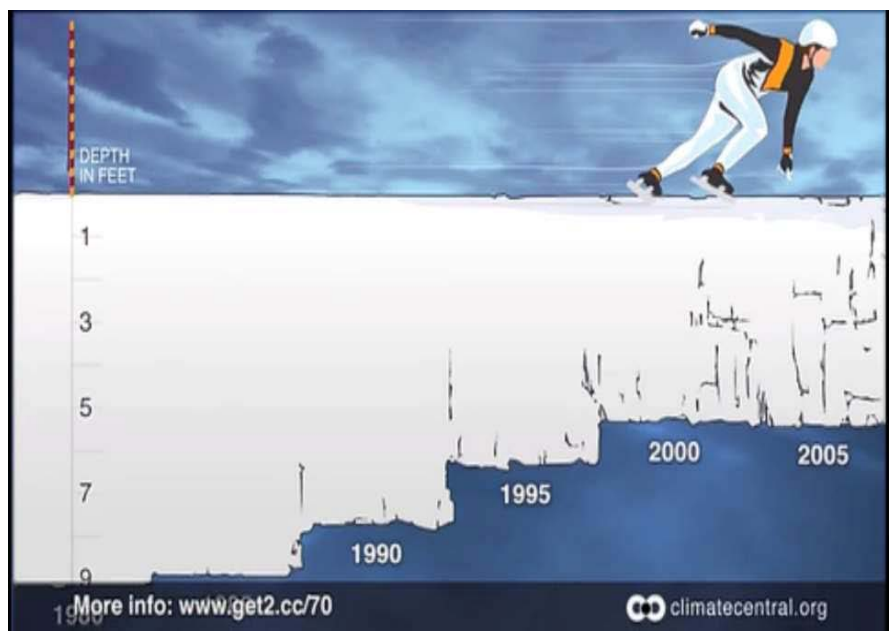

Figure 3. Arctic sea ice minimum volume variation.

Table 1. Average temperature of Oslo in 2018.

\begin{tabular}{ccccccccc}
\hline Annual mean temp. & Jan. & Feb. & Mar. & Apr. & May & Jun. & Jul. & Aug. \\
\hline Daily highest TEMP $\left({ }^{\circ} \mathrm{C}\right)$ & -2 & -1 & 4 & 9 & 16 & 20 & 22 & 20 \\
Daily lowest TEMP $\left({ }^{\circ} \mathrm{C}\right)$ & -7 & -7 & -3 & 1 & 6 & 11 & 12 & 11 \\
Average total PRCP $(\mathrm{mm})$ & 49 & 36 & 47 & 41 & 53 & 65 & 81 & 89 \\
Average days of PRCP (d) & 16 & 12 & 13 & 12 & 13 & 14 & 15 & 16 \\
\hline
\end{tabular}




\subsection{Solar Flare}

According to the observation records of the Beijing Meteorological Museum, at about 08:00 on the evening of September 6, 2017, the solar active area AR12673 unleashed a super flare of X9.3 class, which is the largest flare during the 24th active week. It is also the strongest flare since September 7, 2005. A large number of particles released by solar activity further reduced ozone levels in the atmosphere, resulting in changes in the polar climate and decrease of the Arctic sea ice.

\section{Conclusions and Discussions}

\subsection{Arctic Climate Change}

The most important component of the global climate system is the Arctic Circle, where the Arctic is exposed to the sun all year round, and sea ice refracts sunlight and re-enters the atmosphere to regulate the climate. But with global warming and sea ice melting, the Arctic surface's ability to reflect sunlight is reduced, and permafrost melts and releases harmful gases, causing overgrowth of moss and changing the color of the Arctic surface and making it further absorb sunlight, thereby making the temperature rise and the glaciers melt faster (Serreze et al., 2012).

That Arctic sea ice is disappearing has been known for decades. The underlying cause is believed by all but a handful of climatologists to be global warming brought about by greenhouse gas emissions. Yet the rate of the ice is vanishing confounds these climatologists' models. These predict that if the level of carbon dioxide, methane and so on in the atmosphere continues to rise, then the Arctic Ocean will be free of floating summer ice by the end of the century. At current shrinkage rates, by contrast, this looks likely to happen sometime between 2020 and 2050 (Matsumura \& Yamazaki, 2012). The reason is that Arctic air is warming twice as fast as the atmosphere as a whole. Some of the causes of this are understood, but some are not.

\subsection{Causes of Change}

\subsubsection{Anthropogenic Factors: Greenhouse Gas Emissions}

Human beings have undergone different times since at the beginning of human activities. Before the Industrial Revolution, the Earth was relatively a natural cycle, which was a relatively stable process and had little impact on climate change.

At this time, the diffusion of carbon dioxide is a positive feedback to the earth, which can regulate the ecology and is suitable for the reproduction of living things. However, with the rise of the Industrial Revolution, a large number of natural resources were consumed unchecked, the population continued to expand and forests were cut down, which made many ecosystems unable to restore themselves, and the waste produced by industry further destroyed the ecology. Rising levels of carbon dioxide have caused greenhouse effect to accelerate, 
melting glaciers at the poles, as shown in Figure 4.

According to a recent report by the United Nations Environment Programme, reducing black carbon and ozone in the lower part of the atmosphere, especially in the Arctic countries of America, Canada, Russia and Scandinavia, could cut warming in the Arctic by two-thirds over the next three decades (Gentsch et al., 2015). Indeed, the report suggests, if such measures-preventing crop burning and forest fires, cleaning up diesel engines and wood stoves, and so on-were adopted everywhere they could halve the wider rate of warming by 2050. Without corresponding measures to cut $\mathrm{CO}_{2}$ emissions, this would be but a temporary fix.

Nonetheless, it is an attractive idea because it would have other benefits and would not require the wholesale rejigging of energy production which reducing $\mathrm{CO}_{2}$ emissions implies. Not everyone agrees it would work, though. Gunnar Myhre of the Centre for International Climate and Environmental Research in Oslo (Knoblauch et al., 2013), for example, notes that the amount of black carbon in the Arctic is small and has been falling in recent decades. He does not believe it is the missing factor in the models. Carbon dioxide, in his view, is the main culprit. Black carbon deposited on the Arctic snow and ice, he says, will have only a minimal effect on its reflectivity.

\subsubsection{Natural Factors: Ocean Circulation, Physical Change in the Ice, Short-Term Climate Forcings, etc.}

As the general circulation changes, the warm currents in the tropics continue to warm up, radiating and flowing downstream to the Arctic, thus melting the sea ice in the region, reducing the ability of the Arctic to reflect sunlight, absorbing more heat, further accelerating the melting of glaciers, and creating a vicious circle.

One is physical change in the ice itself. Formerly a solid mass that melted and refroze at its edges, it is now thinner, more fractured, and more liable to melt.

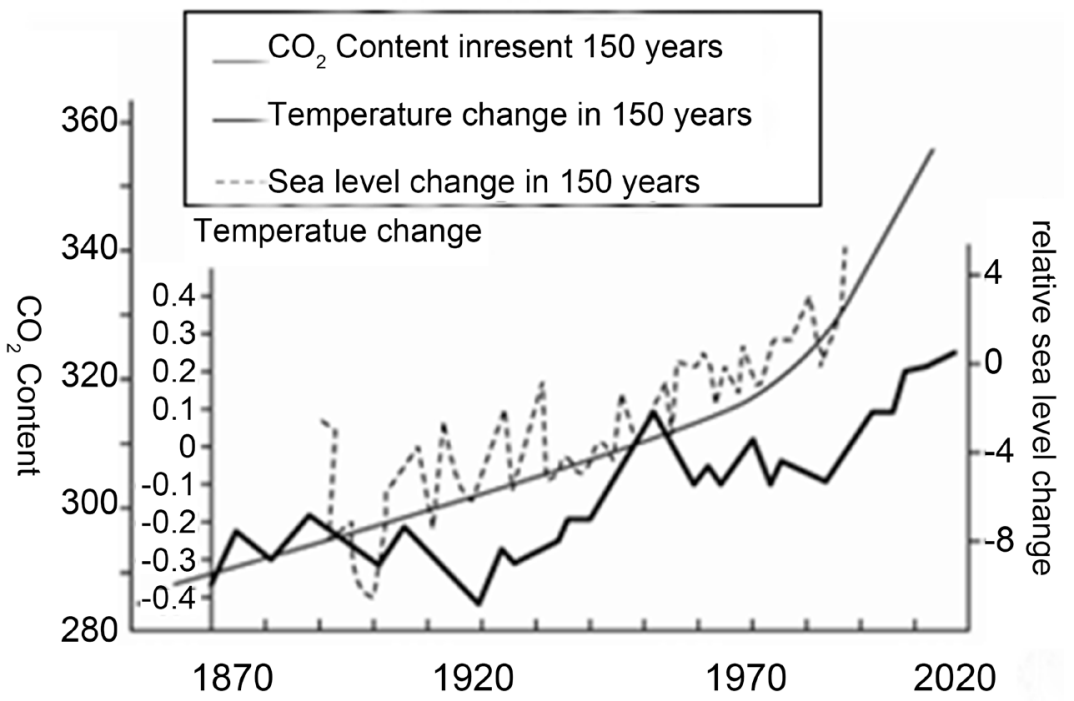

Figure 4. Changes of temperature, sea level and $\mathrm{CO}_{2}$ in Arctic in the recent 150 years. 
But that is a marginal effect. Filling the gap between model and reality may need something besides this (Ricker et al., 2014).

The latest candidates are short-term climate forcings. These are pollutants, particularly ozone and soot, which do not hang around in the atmosphere as carbon dioxide does, but have to be renewed continually if they are to have a lasting effect. If they are so renewed, though, their impact may be as big as $\mathrm{CO}_{2}$ 's.

At the moment, most eyes are on soot. In the Arctic, soot is a double whammy. First, when released into the air as a result of incomplete combustion, soot particles absorb sunlight, and so warm up the atmosphere. Then, when snow or rain wash them onto an ice floe, they darken its surface and thus cause it to melt faster. Reducing soot would not stop the summer sea ice disappearing, but it might delay the process by a decade or two (Perovich et al., 2017).

\subsubsection{Potential Factor: Solar Flares}

Solar flares are a flash that erupt on the surface of the sun, releasing huge amounts of energy. Electromagnetic radiation at all frequencies will increase, accelerating electrons, protons, and heavier ions to be close to the speed of light and constantly bombarding the Earth's atmosphere, and resulting in changes in the Earth's climate (Coyle \& Cooney, 1988).

\subsection{Consequences}

The direct consequences of changes in the Arctic are mixed. They should not bring much rise in the sea level, since floating ice obeys Archimedes' principle and displaces its own mass of water. A darker-and so more heat-absorbent-Arctic, though, will surely accelerate global warming and may thus encourage melting of the land-bound Greenland ice sheet. That certainly would raise sea levels. Wildlife will also suffer. Polar bears, which hunt for seals along the ice's edge, and walruses, which fish there, will both be hard-hit. The effects upon the wider climate are tricky to assess.

Some meteorologists suspect unseasonal snow storms off the east coast of America in 2010 were partly caused by Arctic warming shifting wind patterns. One feedback loop that does seems certain, though, is that the melting Arctic will enable the extraction of more fossil fuel, with all that that implies for greenhouse gas emissions. The Arctic is reckoned to hold approximately $15 \%$ of the world's undiscovered oil reserves and $30 \%$ of those of natural gas. Hence a growing polar enthusiasm among energy companies-as witnessed last month in an Arctic tie-up between Exxon Mobil of America, and Rosneft, Russia's state-controlled oil giant.

Recent plankton blooms suggest a warmer Arctic will provide a boost to fisheries there, too. And the vanishing ice has begun to allow a trickle of shipping across the Arctic's generally frozen north-west and north-east passages, thus linking the Atlantic and Pacific oceans (Stroeve et al., 2012). In August, a Russian supertanker, the Vladimir Tokohonov, aided by two nuclear icebreakers, 
became the first such vessel to cross the north-east route, hugging the Siberian coast.

So far, despite some posturing by Canada and Russia, there are few territorial disputes in the region and the Arctic Council, the club of Arctic nations has functioned reasonably well. Whether the interests of these countries coincide with those of the wider world, though, is moot. A warming Arctic will bring local benefits to some. The rest of the world may pay the cost.

\section{Summary}

This paper summarizes the remarkable performance of Arctic climate change by obtaining data from scientific expeditions. The causes of Arctic climate change are analyzed from three aspects: anthropogenic factors, natural factors and potential factors: a large amount of greenhouse gas emissions caused by human activities, tropical ocean currents, potential solar flares that have changed the Arctic climate, respectively.

\section{Acknowledgements}

My deepest gratitude goes first and foremost to Professor Gao Dengyi, Professor Zhang Mingying and Professor Ma Jingjin for their strong support for this scientific expedition. Second, I would like to express my heartfelt gratitude to the support from the New Aulsson Arctic Research Base and other institutions. Last, my thanks would go to my teammates of the investigation team for their teamwork and hardwork.

\section{Conflicts of Interest}

The author declares no conflicts of interest regarding the publication of this paper.

\section{References}

Coyle, K. O., \& Cooney, R. T. (1988). Estimating Carbon Flux to Pelagic Grazers in the Ice-Edge Zone of the Eastern Bering Sea. Marine Biology, 98, 299-306. https://doi.org/10.1007/BF00391208

Gentsch, N., Mikutta, R., Alves, R. J. E., Barta, J., Čapek, P., Gittel, A., \& Guggenberger, G. (2015). Storage and Transformation of Organic Matter Fractions in Cryoturbated Permafrost Soils across the Siberian Arctic. Biogeosciences, 12, 4525-4542. https://doi.org/10.5194/bg-12-4525-2015

Knoblauch, C., Beer, C., Sosnin, A., Wagner, D., \& Pfeiffer, E.-M. (2013). Predicting Long-Term Carbon Mineralization and Trace Gas Production from Thawing Permafrost of Northeast Siberia. Global Change Biology, 19, 1160-1172. https://doi.org/10.1111/gcb.12116

Lindsay, R., Wensnahan, M., Schweiger, A., \& Zhang, J. (2014). Evaluation of Seven Different Atmospheric Reanalysis Products in the Arctic. Journal of Climate, 27, 2588-2606. https://doi.org/10.1175/JCLI-D-13-00014.1

Liu, J., Curry, J. A., Wang, H., Song, M., \& Horton, R. M. (2012). Impact of Declining Arctic Sea Ice on Winter Snowfall. Proceedings of the National Academy of Sciences, 
109, 4074-4079. https://doi.org/10.1073/pnas.1114910109

Matsumura, S., \& Yamazaki, K. (2012). Eurasian Subarctic Summer Climate in Response to Anomalous Snow Cover. Journal of Climate, 25, 1305-1317. https://doi.org/10.1175/2011JCLI4116.1

Perovich, D. K., Richter-Menge, J. A., Elder, B., Claffey, K., \& Polashenski, C. (2017). Observing and Understanding Climate Change: Monitoring the Mass Balance, Motion, and Thickness of Arctic Sea Ice. Cold Regions Research and Engineering Laboratory.

Ricker, R., Hendricks, S., Helm, V., Skourup, H., \& Davidson, M. (2014). Sensitivity of CryoSat-2 Arctic Sea-Ice Freeboard and Thickness on Radar-Waveform Interpretation. Cryosphere, 8, 1607-1622. https://doi.org/10.5194/tc-8-1607-2014

Serreze, M. C., Barrett, A. P., \& Stroeve, J. (2012). Recent Changes in Tropospheric Water Vapor over the Arctic as Assessed from Radiosonde and Atmospheric Reanalyses. Journal of Geophysical Research, 117, Article ID: D10104. https://doi.org/10.1029/2011JD017421

Solomon, S., et al. (2007). Climate Change: The Physical Science Basis. Cambridge: Cambridge University Press.

Stroeve, J. C., Kattsov, V., Barrett, A., Serreze, M., Pavlova, T., Hollamd, M., \& Meier, W. N. (2012). Trends in Arctic Sea Ice Extent from CMIP5, CMIP3 and Observations. Geophysical Research Letters, 39, L16502. 